\title{
Food Waste-to-Energy
}

A project-based school learning experience
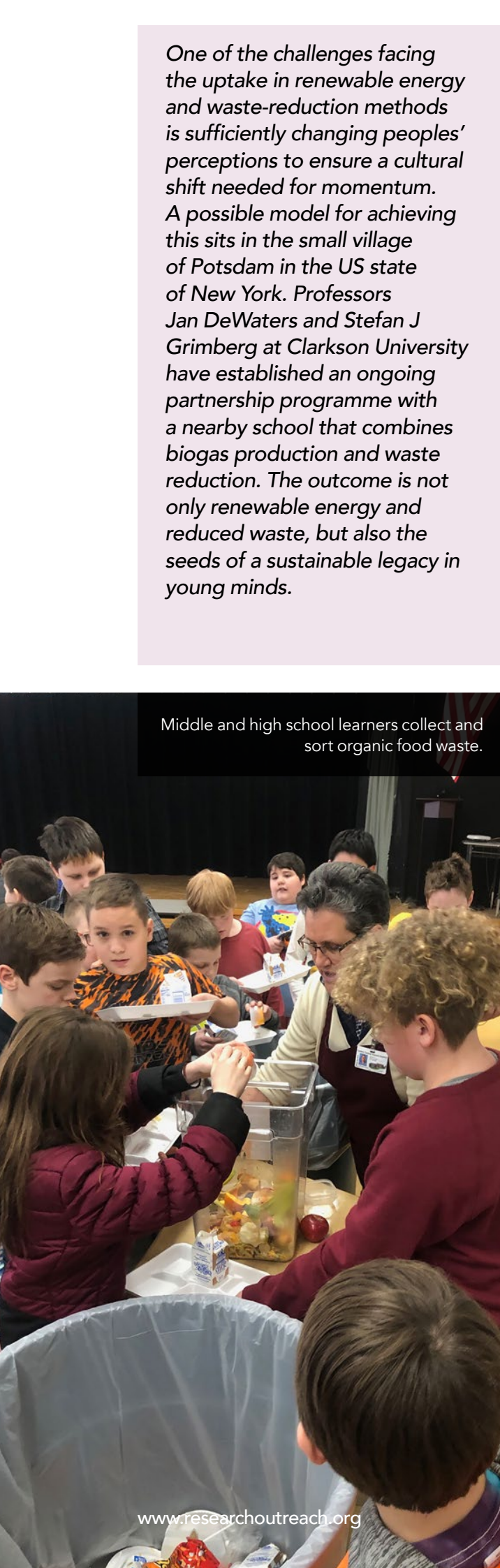

$\bigcup_{\text {is probably the ugly cousin }}^{\text {ithin the renewable energy }}$ hotovoltaic systems and majestic, slowly whirring wind turbines But it has an ace up its sleeve: it does three things, not just one. Anaerobic digesters, which lie at the heart of biogas
production, sem microorganisms to break production, use microorganisms to break of oxygen to produce the biogsances for heating The residue - or digestate -remains rich in nutrients, making it an excellent fertiliser, But the real gem is that feeding this whole process is organc waste. So, not only does the system produce gas and fertilicer it also rem organic materials from the solid waste system. This is a significant drawcard because the scope of food waste in the US alone is staggering.

According to the US National Resources Defense Council, approximately $40 \%$ of all food produced in the US - ove 90 million tonnes per year - ends up uneaten. This wastage occurs
throughout the entire food supply chan throughout the entire food supply chain, from production through delivery to food waste ends up in landfills. In fact, food waste is the single largest fract, of material in landfills. Notonty does it diminish landfill capacity, but in its decomposition, it generates gases. The issue is so dire that one of several states - New York - has mandated that as of 2022, any facility generating more than 1.8 tonnes of food waste a year will not be allowed to landfill its organic waste. Students in a small border are exploring one solution to the problem.

A YOUNG IDEA GROWS Potsdam may be small as towns go, but it punches above its weight in tertiary of those is Clarkson University, a private and the home of the ood-to-Energy programme headed by Professors Jan DeWaters and

The programme's genesis came from the high school environmental club ( Canton Central School (CCS) in were intering Canton. The learners use food waste from their cafeteria in the anaerobic digester on a nearby farm. The farm is part of the Cornell Cooperative Extension at Saint Lawrence County (CCE), an educationa outreach facility focused on food and agricultural systems.

Inspired by the learners, DeWaters and Grimberg developed the idea into a three-way partnership. It works like this: the school's middle and high school learners collect and sort organic food waste from their cafeterias. The university students collect the waste from the is the f fed into the the CCE farm. It is then fed into the anaerobic digester, producing biogas to heat a greenhouse recovered solids, and fertiliser. But there's so much more to the partership than steady stream of waste-to-fuel, and it's

Education is central to the whole programme, and for a good reason. It is well-known that long-term behavioural change originates in early experience. It's easier to plant the seed of behavioural change in a young mind than it is to reform a habituated adult. Furthermore, young minds are fertile grounds for environmental issues - hyper-connected, social media-savvy youth are part of the popular groundswell to address climate change. lits no accident that the school learners.

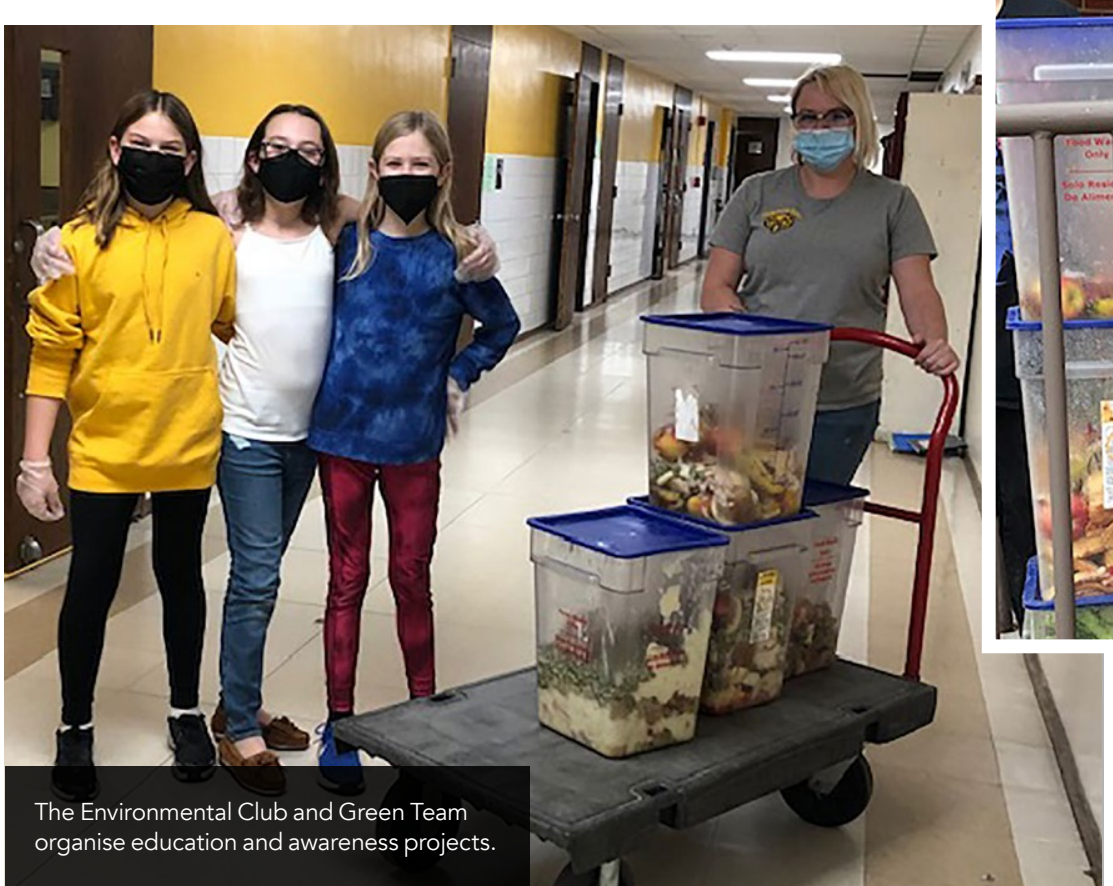

The separation and collection of food waste is actually only one part of a much broader education programme involving classroom and extracurricular activities in resource recovery. DeWaters and Grimberg knew that if the programm was to succeed in changing the learners' long-term behaviour, it must do three things: make the learners aware of the problem, increase their understanding of the solution, and increase their participation in the solution. In essence, the school must become a living laboratory.

EDUCATION AT MULTIPLE LEVELS Education throughout the programme happersity students are engaged in a credit-bearing course. They help design project-based activities for the high school learners on food waste, anaero digesters, and biogas production. These are presented together with teachers. One of the most popular is a science class experiment where students build small anaerobic bioreactors using sma mouthed glass bottles and balloons. Microorganisms digest organic materia in the bottles, producing gas that blows up the balloon

At the same time, teachers incorporate other project components into lessons meet class-specific learning objectives.

For example, environmental science classes estimate the biogas produce resulting impact on electricity-related $\mathrm{CO}_{2}$ emissions, and chemistry classes learn the stoichiometry and biogas potential for digesting various types of food waste. At the peer level, the high The learners use posters and other
Approximately $40 \%$ of all food roduced in the US - over 90 million onnes per year - ends up uneaten. school Environmental Club and the middle school Green Team - an active group of 5 th and 6 th graders - drive forms of peer contact to encourage awaress of food waste and its imparts. Educating other learners to sort their
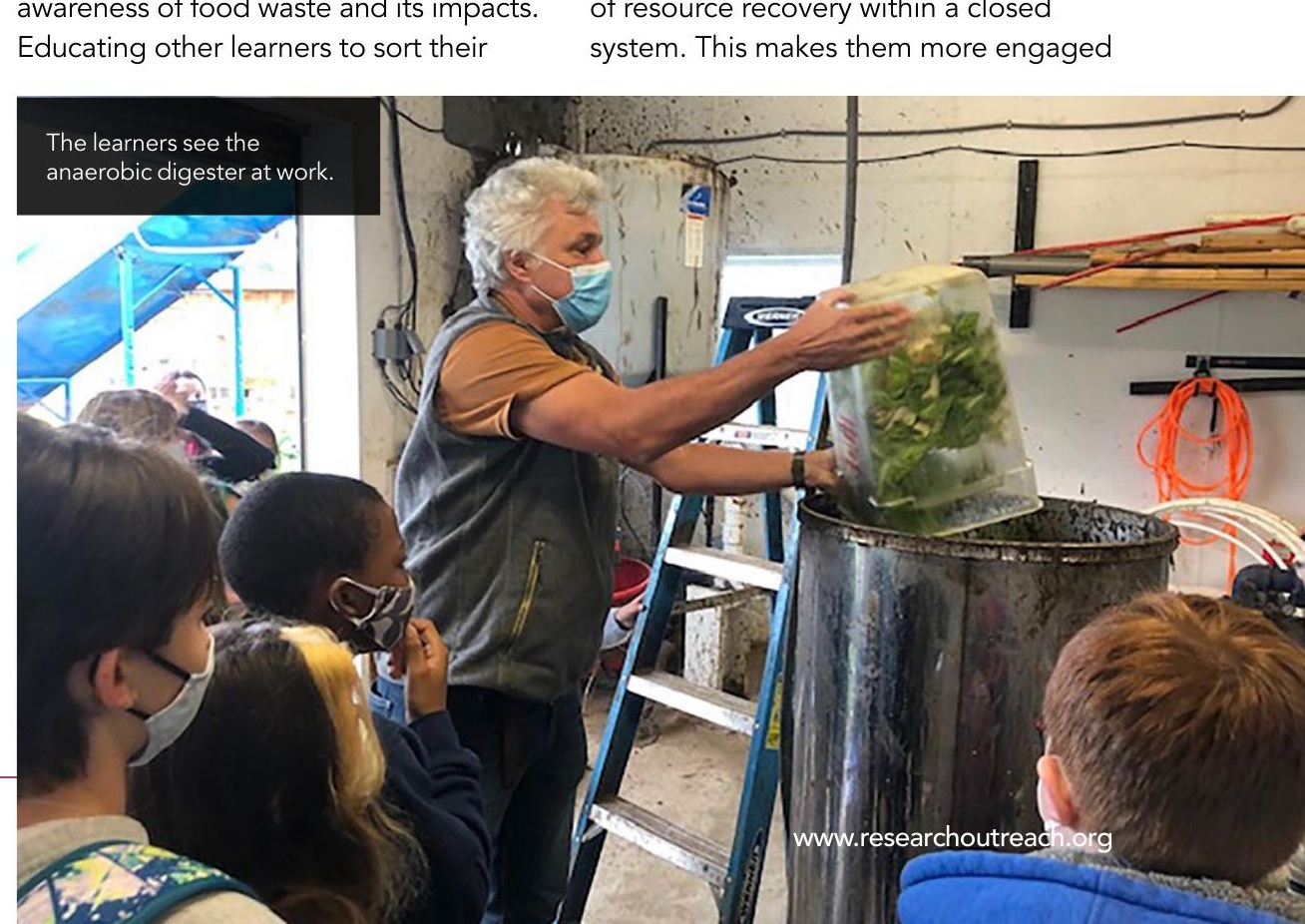
